\title{
PANDEMIA E LAZER: OS REFLEXOS DA PANDEMIA NOS COTIDIANOS DE LAZER DAS PERIFERIAS URBANAS
}

\author{
Lourenço Cezar da Silva \\ Mestre em Educação pela Universidade Federal do Rio de Janeiro e membro fundador do \\ Núcleo de Estudos e Pesquisa Social da Maré (NEPS), Rio de Janeiro/RJ, Brasil \\ lourencocezar@hotmail.com
}

Diogo Silva do Nascimento Pesquisador no Núcleo de Estudos e Pesquisa Social da Maré (NEPS), Rio de Janeiro/RJ, Brasil dyogo.edu@gmail.com

Marcelo Ribeiro Sales Doutorando em Serviço Social pela Universidade Federal do Rio de Janeiro (UFRJ), Rio de Janeiro/RJ, Brasil grigh2@yahoo.com.br

Rafaela Goltara Souza Mestre em Educação, Cultura e Comunicação em Periferias Urbanas (PPGECC) pela Universidade Estadual do Rio de Janeiro (UERJ), Rio de Janeiro/RJ, Brasil rafaelagoltara@gmail.com

\section{RESUMO}

Diversas periferias no país são marcadas historicamente por ausências, precariedade dos serviços públicos e pelas narrativas sobre violência e pobreza divulgadas pela imprensa de forma constante há muitas décadas. Essas narrativas oficializadas sobre esses territórios imperam como obstáculos aos moradores, que continuam sendo estigmatizados e excluídos socialmente. Nestes tempos de pandemia, a situação parece ter se agravado. Falta de leitos para a população mais pobre, materiais de higiene e até mesmo a diminuição drástica da renda tem tensionado esse período nos territórios periféricos. No entanto, mesmo com tantas problemáticas, muitos moradores de periferias têm encontrado dificuldade de abrir mão dos espaços de lazer, mesmo com medidas de distanciamento social. Nesse sentido, as resenhas nos botequins, as peladas no campo de várzea, o bate papo nas feiras se apresentam como grandes adversários nessa luta contra a COVID-19. Assim, buscando entender as relações e a importância que esses territórios do lazer representam, buscamos investigar três periferias nos estados de Minas Gerais e Rio de Janeiro. Nessa perspectiva, pesquisamos os bairros de Justinópolis em Ribeirão das Neves-MG, Lote XV em Belford Roxo-RJ e o Conjunto de Favelas da Maré no Rio de Janeiro-RJ. O trabalho analisou a maneira como se configuraram as sociabilidades e identidades tecidas através das experiências fomentadas nesses espaços de lazer, indicando a resistência dos moradores em abrir mão, mesmo em um momento de pandemia, desses espaços de lazer.

Palavras-chave: Lazer. Lugar. Favela. Periferias Urbanas. 


\title{
PANDEMIC AND LEISURE: THE REFLECTIONS OF PANDEMIC IN LEISURE DAYS IN URBAN PERIPHERIES
}

\begin{abstract}
Several peripheries in the country have historically been marked by absences, precarious state services and the narratives about violence and poverty that have been constantly published by the press for many decades. These official narratives about these territories reign as obstacles to residents, who continue to be stigmatized and socially excluded. In these pandemic times, the situation seems to have worsened. Lack of beds for the poorest population, hygiene materials and even the drastic decrease in income has tense this period in the peripheral territories. However, even with so many problems, many residents of peripheries have found it difficult to give up leisure spaces, even with measures of social isolation. In this sense, the reviews in the taverns, the naked ones in the lowland field, the chat at the fairs present themselves as great opponents in this fight against COVID-19. Thus, seeking to understand the relationships and the importance that these leisure territories represent, we seek to investigate three peripheries in the states of Minas Gerais and Rio de Janeiro. In this sense, we researched the neighborhoods of Justinópolis in Ribeirão das NevesMG, Lote XV in Belford Roxo-Rj and the Set of Favelas da Maré in Rio de Janeiro- RJ. The work analyzed the way in which the sociability and identities woven through the experiences fostered in these leisure spaces were configured, indicating the resistance of residents to give up, even in a pandemic moment, these leisure spaces.
\end{abstract}

Keywords: Leisure. Place. Shanty town. Urban peripheries. 


\section{INTRODUÇÃO}

O ano de 2020 marcou a história da humanidade devido à grave crise sanitária causada pela COVID-19 ${ }^{1}$. Com o espalhamento do vírus em nível global, que, segundo a maioria da comunidade científica surgiu na China, a doença trouxe medo e perplexidade ao mundo. Esse sentimento foi crescendo à medida que a situação indicava a emergência de uma pandemia, atingindo novos países e causando perdas de milhares de vida.

No Brasil, a postura negacionista do governo federal destonou das ações de muitos governos estaduais e municipais que criaram ações de restrição ao convívio social e ao aumento de leitos e testes (detectar a doença) para grande parte da população. Assim, como o Presidente estadunidense ${ }^{2}$, o Presidente brasileiro ${ }^{3}$ minimizou os efeitos da pandemia, negando-se a reconhecer a gravidade do vírus e a importância das medidas restritivas.

O caso brasileiro de combate à pandemia tem se tornado emblemático no contexto mundial. Além de ações e discursos difusos parte de muitos governantes, principalmente do governo federal, a pandemia se associou aos problemas políticos e econômicos criando o que setores da mídia estão chamando de tempestade perfeita. Enquanto isso, o país já ultrapassou a marca das 200 mil mortes.

Tal situação foi mais dramática nas periferias urbanas do país. A grande desigualdade social, a precariedade de serviços públicos e a violência urbana fizeram a pandemia ter mais impactos nesses territórios. As autoridades sanitárias recomendavam um distanciamento social, mas como fazer distanciamento em casas com cinco, seis ou mais morando em casas com 15/20 metros quadrados? Se alguém fosse infectado, inevitavelmente iria contaminar outros moradores da casa.

\footnotetext{
${ }^{1}$ Segundo o Ministério da Saúde A COVID-19 é uma doença causada pelo coronavírus, denominado SARS-CoV-2, que apresenta um espectro clínico variando de infecções assintomáticas a quadros graves (ORGANIZAÇÃO PANAMERICANA DE SAÚDE, 2020).

2 Donald Trump foi presidente dos Estado Unidos no período de 2017-2021.

3 Jair Messias Bolsonaro foi eleito em 2018.
} 


\section{COMO FICAM AS FAVELAS (?)}

No desenho desse novo cenário, não se notou, de imediato, a preocupação com os territórios periféricos. Esses espaços, há mais de um século, sofrem com o papel desempenhado pelas mídias por criarem um imaginário negativo, de forma espetacularizada (SÁNCHEZ, 1997), criando "verdades" que acabam contribuindo para representações acerca de sua presença dentro da cidade.

Para além desses estigmas sociais criados midiaticamente, vale ressaltar que as periferias produzem signos de bem-estar e satisfação no consumo dos espaços de lazer, criam comportamentos e estilos de vida e promovem a valorização e pertencimentos aos lugares. Em outras palavras, celebra os seus territórios a partir de uma rede de relações sociais muito forte. Isso se torna importante para entender a construção desses lugares periféricos, bem como sobre as pessoas desses espaços. Nesse sentido, segundo Paulo Freire, "carregamos conosco a memória de muitas tramas, o corpo molhado de nossa história, de nossa cultura; a memória, às vezes difusa, às vezes nítida, clara, de ruas da infância, da adolescência; a lembrança de algo distante que, de repente, se destaca límpido diante de nós" (FREIRE, 2014, p. 45).

E qual o impacto da COVID-19 nas periferias? Como esperar o combate a um vírus tão letal em um lugar onde tarefas simples de higiene como lavar as mãos e distanciamento social (em casas pequenas e ou em favelas onde até a circulação do ar é prejudicada) estão entre os maiores limites dessa população? Segundo dados de Peres (2020), a possibilidade de exigir que um morador de Favela faça o distanciamento se ausentando do trabalho por uma semana, pelo menos, poderia impactar na vida de $72 \%$ dos moradores. Fatores como esses explicam por que - nas favelas do Rio, que não contam com a ajuda efetiva do município do Rio -, a políticas de fiscalização contra aglomerações é, assim como outras, inexistente.

As problemáticas socias que historicamente acompanham as favelas nos reorientam a pensar a COVID-19 como um desafio avassalador para esses territórios. Nesse sentido, as indagações de Claudia Miranda (2015, p. 38) são também as nossas: “Como a invisibilidade dos já reconhecidos quilombos urbanos emerge como um desafio (...) como mobilizar os sujeitos diretamente implicados nessa arena de disputa pela vida?". 
Todavia, não podemos deixar de lembrar que as décadas de descaso com saúde, moradia, segurança, dentre vários outros direitos historicamente negados à população mais pobre, seria mais um ingrediente à fragilizar as ações nesse momento. A questão da renda é muito importante, mas no caso brasileiro temos outras mazelas a serem consideradas como, por exemplo, as habitações, saneamento, o acesso à água, coleta de lixo regular, acesso à saúde, transporte e educação, questões que contribuem para um cenário perfeito de proliferação da COVID-19. Nesse contexto, as periferias, lócus preferencial do descaso público, deveriam ser o local onde o Estado garantisse especial prioridade, no entanto, isso não tem acontecido e os números estão demonstrando essa realidade em diferentes partes do país.

\section{A PANDEMIA E SEUS RECORTES SOCIAIS}

Nas semanas de abril e maio de 2020, em que os hospitais estavam com a carga máxima de pacientes e o número de mortes aumentando, foi possível observar uma sensação de medo nos moradores das periferias da Maré (Rio de janeiro-RJ), Justinópolis (Ribeirão das Neves-MG) e Lote XV (Belford Roxo- RJ). Os intensos vai-e-vem, comuns na rua principal da Vila do João (Conjunto de Favelas da Maré), na Praça da matriz (Justinópolis) e na "rua da feira" (Lote XV), deram lugar para lojas fechadas, poucas pessoas nas ruas e uma grande procura por álcool em gel e máscaras.

Na Maré, o famoso campeonato de "peladas" do campo da Toca suspendeu os jogos, e até mesmo as famosas feiras da Teixeira e da Vila do João deixaram de estender suas lonas. A COVID-19 fomentou uma nova rotina social e também higiênica a todos nós. Cidades e vias fechadas, transporte público restrito, áreas de lazer fechadas, toque de recolher e uma imensa e inquietante sensação de pavor perante o crescente número de mortos e a proximidade da doença em nossos laços familiares, de amizade e vizinhança.

Nas primeiras semanas da implementação das medidas restritivas e notícias sobre a falta de leitos e aumento do número de mortes, os moradores acabaram respeitando as medidas e surgiram até mesmo notícias de que grupos criminosos impuseram algumas "proibições" aos moradores de algumas Favelas do Rio de Janeiro.

Tráfico impõe toque de recolher e uso obrigatório de máscaras em favelas do Rio durante a pandemia 
Em diferentes favelas do Rio, desde a tarde desta quarta-feira (6), moradores passaram a receber mensagens de texto e áudio, através telefone celular, ou carros de som com, alertas para não circularem pelas ruas de comunidades depois das $10 \mathrm{~h}$. Em todas as mensagens, há ameaças para quem não cumprir as ordens.

Moradores ouvidos pelo G1 confirmam que há um toque de recolher em comunidades das Zonas Norte, Oeste e na região central da cidade numa tentativa de conter o avanço do coronavírus.

De acordo com os comunicados, os moradores estão proibidos de ficar nas ruas a partir das 20h. Estão proibidas as "resenhas, pagodes, festas", além das reuniões em praças e quadras.

Os encontros em bares e comércios estão proibidos. Os moradores dessas localidades devem apenas comprar os produtos e retornar às suas casas. Sempre de máscaras. Todas mensagens são acompanhadas de ameaças a quem não cumprir as ordens. (LEITÃO; MARTINS, 2020).

O que se viu foram inúmeros moradores com medo, principalmente pelas problemáticas sociais que as periferias já apresentam, como a precarização do saneamento básico e o acesso aos sistemas de saúde. Além disso, por ter inúmeros moradores trabalhando informalmente ou, segundo a atual política neoliberal, sendo empreendedores, as medidas restritivas atingiram em cheio esses trabalhadores.

Vendedores de frutas das principais ruas de comércio em Justinópolis, camelôs das ruas do Lote XV e vendedores de biscoitos na linha vermelha, altura da Maré, e tantos outros trabalhadores informais sofreram instantaneamente os efeitos das medidas de combate à COVID-19.

Nesse processo, várias redes de solidariedade surgiram, tais como a Frente Maré no Rio de janeiro, Nossos Irmãos em Belford Roxo- RJ e Coletivo Balaio em Ribeirão das Neves MG, com o intuito de ajudar um grande número de moradores que estavam sem renda e com grande dificuldade de conseguir o auxílio emergencial, devido à ausência de documentos e à burocracia imposta pelo próprio governo. Essas ações de solidariedade, conhecidas nas periferias como mutirões, é uma característica histórica desses territórios. Segundo Magnani (1984), bater laje, fazer a encanação da rua, tampar buracos, tudo isso já faz parte desse cotidiano social.

\footnotetext{
A maneira como se utiliza os sistema de mutirão, por exemplo, para a construção de casas na periferia, apresenta uma dinâmica em alguns aspectos diferente à dos padrões que caracterizavam o emprego desta forma de trabalho cooperativo, nas lides do campo: o recurso à mão de obra de parentes e vizinhos, cedida gratuitamente ou sob regime de reciprocidade (MAGNANI, 1984, p. 27)
} 
Contudo, mesmo com o avanço da doença e das medidas restritivas, observamos muitos moradores voltando às suas rotinas de lazer. Assim, campos, bares e praças voltaram a ser usadas como prática de lazer. Ao observarmos esse processo, começamos a nos questionar sobre o motivo das atitudes de muitos moradores em voltar a frequentar esses espaços mesmo com o risco de contraírem a doença, já que o crescimento da COVID-19 e a escassez de leitos nos hospitais eram noticiados a todo o momento.

A partir das inquietações que surgiram, buscamos não olhar para essas atitudes de maneira reducionista, classificando-as como meras atitudes irresponsáveis, imprudentes e negligentes. Buscamos, assim, criar novos olhares sobre possíveis outras relações envolvidas nessas atitudes. Olhares que pudessem elucidar a ligação dos moradores com esses espaços de lazer. Através da análise de pesquisadores/moradores do contexto periférico, que tem buscado entender esses territórios sob a ótica de narrativas para além dos estigmas sociais, elaboramos um estudo com o intuito de entender melhor as relações dos moradores com as práticas de lazer nesse período de pandemia.

Em uma primeira abordagem sobre o tema, percebemos que tínhamos feito um processo conhecido como "descrição densa", termo utilizado por Clifford Geertz (1989) para explicar o processo etnográfico. A partir da densidade dos relatos e entendendo as características geográficas que envolvem os espaços periféricos, procuramos explorar esses contextos a partir dos estudos de José Guilherme Magnani (2002) que propõe uma etnografia urbana, um jeito de pesquisar com um olhar "de perto e de dentro", que valorize tanto os atores sociais que serão estudados quanto a paisagem em que a atividade se desenrola como sendo parte constitutiva da situação em análise. Ou seja, um olhar que enxerga os diversos "pedaços" existentes nesses territórios.

Nesse sentido, entendendo que "habitar é narrativizar", como diz Certeau (2013, p. 201), resolvemos pesquisar três periferias urbanas: Lote XV (Belford Roxo- RJ), Justinópolis (Ribeirão das Neves- MG) e Conjunto de Favelas da Maré (Rio de Janeiro-RJ) nos períodos que antecederam a "flexibilização" das restrições sociais. Observamos um grande apego de diversos moradores pelas rotinas de lazer; desde jogos em campos de várzea, a cervejinha nos botequins, aos rolês de skates na praça, abrir mão dessas práticas de lazer e de estar nesses lugares de lazer apresentou-se como um grande desafio para o cumprimento das medidas restritivas que envolvem o combate à COVID-19. 
Em virtude dos desafios metodológicos impostos pelas medidas de distanciamento social, buscamos observar atentamente o cotidiano nas nossas restritas andanças pelos territórios citados. Nesse processo conseguimos fazer importantes observações, narrativas e reflexões sobre as dificuldades dos moradores abrirem mão dos seus lugares de lazer, como podemos observar abaixo.

\section{CENA 1- CONJUNTO DE FAVELAS DA MARÉ, RIO DE JANEIRO-RJ4}

É sábado na Favela da Maré no subúrbio do Rio de Janeiro. Um sábado de sol com tempo ameno em um típico dia de outono. Nas ruas é possível avistar moradores varrendo suas calçadas, conversando com os vizinhos e tantos outros indo ao sacolão, que tem ficado bem cheio devido às proibições das feiras no período de quarentena.

Além do barulho das vassouras nas calçadas, os mais jovens logo tratam de iniciar os preparativos para o bailar das pipas. Um bailar marcado por pipas grandes, pipas pequenas e, quando o vento está forte, surgem até mesmo pipas feitas de sacola plástica, conhecidas na região por giriquinhos. Nesses entardeceres de outono, as pipas abrilhantam ainda mais o lindo "alaranjado" que é marcante nessa época do ano. Outros jovens preferem iniciar as brincadeiras na rua logo cedo. Taco, golzinho, queimado, diferentes piques e até mesmo circuitos de bicicleta e carrinho de rolimã fazem parte dos finais de semana sem operação policial.

Ao longo da tarde, churrascos e concentração de torcidas surgem nas ruas para assistirem as reprises de grandes jogos que têm sido exibidos nas redes de televisão nesse período de restrições sociais. Se nas primeiras semanas das restrições muitos espaços etílicos

\footnotetext{
${ }^{4}$ Por ser um local historicamente marcado pela "ausência" (ZALUAR, 2003), o Conjunto de favelas da Maré explicita a precariedade ou omissão de políticas públicas e a situação de exclusão social, configurando claramente, como assinala Alba Zaluar (2003), "uma manifestação de injustiça distributiva”. A Maré é constituída por diferentes localidades e conjuntos habitacionais na região da zona norte do Rio de Janeiro. De acordo com o índice de desenvolvimento humano, a Maré está entre os três piores bairros da cidade (CENTRO DE ESTUDOS E AÇÕES SOLIDÁRIAS DA MARÉ, [2003?]). Isso exemplifica a realidade em que vivem os habitantes residentes desta área.

Situada entre a avenida Brasil e Linha Vermelha e cortada pela Linha Amarela - as três principais vias da cidadea Maré emerge como um imenso conjunto de favelas, com a presença de cento e trinta e dois mil moradores, distribuídos em dezesseis (16) comunidades. O fato de estar próxima ao aeroporto Internacional e vizinha à Universidade Federal do Rio de Janeiro contribui para que ocupe uma presença significativa no imaginário carioca, sendo representada como um espaço globalmente dominado pela miséria e pela violência.
} 
ficaram vazios, após o início das reprises, os bares da Dona Marina, do Seu Zé, do Itamar e do Oliveira voltaram à rotina com mesas que tomam parte da rua, promoções de cerveja e petiscos e até mesmo churrascos e comemorações de aniversário.

No outro lado da Favela, no campo da Toca, às sete da manhã já é possível avistar alguns senhores de cabelo grisalho chegando ao campo. Se trata da conhecida pelada de veteranos que acontece todos os sábados às $8 \mathrm{~h}$. Aos finais de semana, o campo chega a receber cerca de 20 jogos divididos em diferentes horários, inclusive à noite. Jogos que abrangem diferentes idades e gêneros.

Em volta do campo, o que é comum em muitos campos da Maré, alguns bares cravam sua existência desde muitas décadas. Alguns deles apresentam características ainda rústicas com petiscos (ovos coloridos, sardinha frita, mocotó) e no máximo duas marcas de cervejas disponíveis e garrafas de diferentes cachaças que ficam logo à vista para quem chega ao local. Um típico "botequim", como é conhecido na região. As características desses "botequins" apresentam muitos contextos familiares, em que o dono ou dona é o único funcionário do estabelecimento e o botequim faz parte da casa. Esses espaços apresentam algumas características importantes. Uma delas é que o número de funcionários depende muito da vida ou morte do dono. Quando vivo, são marcados por apenas um funcionário, o próprio dono. Quando morto, o atendimento é feito por outros funcionários como filhos, esposa, netos e outros parentes, já que se trata de uma fonte de renda imprescindível para as respectivas famílias.

São nesses bares que ocorrem resenhas após os jogos. Na verdade, esses lugares se apresentam como extensão do campo. Já no intervalo dos jogos, entre um tempo e outro, muitos jogadores vão lá "calibrar", como eles dizem, já os que ficam na reserva já ficam por lá mesmo aguardando a sua vez na partida.

Neste sábado, o clima está bem festivo devido a realização da Liga da toca de Futebol Amador (LIFA). Muitos jogadores e torcedores nos botequins, ao redor do campo e em uma pequena arquibancada atrás do gol. Vale destacar que o grande número de pessoas assistindo pode ter sido influenciado, além do boca-a-boca, pelas publicações da Liga nas redes sociais. A Liga tem uma página no Facebook com 4.208 pessoas acompanhando as publicações referentes aos jogos, resultados e horários em que os times irão jogar. Em publicação feita na manhã deste sábado, a Liga destacou os confrontos do dia: 
A bola rola a partir de hoje às 16:20, com 2 grandes jogos. 0 primeiro jogo da tarde temos o confronto entre caju, representado pelos blues do Chelsea, contra parada de Lucas, representado pelos lobos do Horta.

No segundo jogo do sábado o Pura Amizade entra em campo pra defender a liderança contra o união da vila que pra continuar sonhando com a classificação. Só a vitória interessa! (LIGA DA TOCA PINHEIRO, 2020).

Terminado os jogos já à noite, surge um aumento significativo de motos nas ruas. Com suas mochilas térmicas, eles cortam ruas, becos e até mesmo calçadas para seguir nas suas entregas. Mesmo com um fluxo de entrega intenso, é comum avistar bares cheios com suas mesas nas ruas e música ao vivo rolando. Em algumas ruas foi possível avistar bolos, salgadinhos, bolas, pula-pula e enfeites de festas de aniversário acontecendo.

\section{CENA 2 - JUSTINÓPOLIS - RIBEIRÃO DAS NEVES- MG 5}

Segunda-feira, 7h30, meu celular começa a apitar com notificações de mensagens dos primeiros diálogos do dia no grupo de WhatsApp da Just Crew Skateboard. "Xia, galera! Quem vai colá na pistinha daqui a pouco?”; “Dá o papo Sea, e esse jeito de chuva?”; “Acabei de acordar, galera já tá chegando lá. Quem puder colá, revitalizar a pistinha de skate do Santa Fé, bora! Xiaa!”; “Demorô, demorô. Vou só tomar um café aqui e tô subindo pra lá, demorô?”; "Tão vão né, daqui a pouco tô brotando na pistinha também"; "Pô gente, tô ralando. Mas mais tarde eu passo lá, se estiver rolando ainda".

Apesar da preocupação com a pandemia e o medo da contaminação, o grupo de skatistas da Just Crew não consegue mais ficar em casa. Ao longo dos últimos três anos, eles conquistaram diferentes pedaços de Justinópolis, distrito do município mineiro de Ribeirão das Neves, como espaços de encontro e prática de skate para os jovens: o coreto da Praça da Matriz, o estacionamento da Paróquia Nossa Senhora da Piedade e a escola Curumim, que estava abandonada e hoje é ocupada por diversos coletivos jovens da região.

\footnotetext{
5 Ribeirão das Neves é historicamente conhecida como "cidade-dormitório", uma vez que a maior oferta de empregos está no município vizinho (Belo Horizonte), que fica a cerca de $30 \mathrm{~km}$ de distância. Além disso, a população aumentou com o crescimento da população carcerária, fator que também gera um estigma aos habitantes por serem reconhecidos como moradores da cidade dos presídios (Neves possui seis unidades prisionais com mais de cinco mil detentos, incluindo o Presídio de Segurança Máxima Dutra Ladeira). Muitos escondem que moram na cidade por medo de não encontrarem serviço em Belo Horizonte, além de não se orgulharem de serem cidadãos nevenses. Contudo, além de ser conhecida como cidade dos presídios, em 2013, uma publicação do Diário Oficial do Estado de Minas Gerais citava a cidade com o nome "Ribeirão das Trevas", e foi amplamente divulgada pela mídia mineira e inclusive de circulação nacional, como a Folha de São Paulo.
} 
A Ocupação Curumim é hoje um dos locais centrais de encontro da crew, pois lá montaram o Centro de Treinamento Avançado para skatistas que já tem prática e experiência na modalidade, e também é o local onde oferecem oficinas gratuitas para iniciantes que querem aprender a dar os primeiros ollies com seus carrinhos. Foi num desses encontros na ocupação que eles decidiram que estava na hora de reformar a antiga pista de skate do bairro Santa Fé, em Justinópolis.

Essa pista é antiga, segundo Davidson Meirelles - um dos skatistas mais experientes da crew -, a prefeitura recebeu uma verba destinada para sua construção, mas nunca finalizou a obra. Apesar de ter sua estrutura pronta, a pista estava cheia de buracos e irregularidades que tornavam inviável sua utilização pelos jovens, uma vez que poderia causar acidentes e lesões corporais. Com a paralisação das atividades escolares e mais jovens em casa com tempo ocioso, a crew sentiu a necessidade de ter mais um espaço destinado à prática e também ao ensino do skate, já que é dessa maneira que eles contribuem com a educação de crianças e jovens nos momentos em que os espaços formais de educação falham.

Depois de ver essa troca de mensagens, comecei o dia preparando meu café e tentando convencer meu pai a usar máscara para ir trabalhar, mesmo que o pessoal do ônibus não esteja fazendo isso. Meu pai é segurança de um supermercado grande que fica localizado na região da Pampulha, em Belo Horizonte. Para chegar no horário certo, ele precisa pegar um ônibus circular que passa no nosso bairro e ir até a estação de integração do MOVE Justinópolis, ônibus que transportam a população de Ribeirão das Neves até pontos do centro de Belo Horizonte, capital mineira. Depois do MOVE, ele ainda pega mais uma condução para chegar até ao bairro em que fica o supermercado.

Ou seja, só nesse dia, ele se expõe a um ambiente fechado com aglomeração de pessoas três vezes para ir e três vezes para voltar. Como já tem 60 anos de idade e alguns problemas de saúde que o colocam no grupo de risco, a preocupação com ele aumenta. A pandemia deixa ainda mais evidente um problema antigo enfrentado pelos nevenses: a frota ineficaz de ônibus MOVE.

Se no dia a dia, a circulação de ônibus já não atende a demanda e faz com que os veículos estejam sempre lotados, especialmente nos horários de pico, com o aviso de paralisação das atividades comerciais em Belo Horizonte esse número de veículos foi reduzido ainda mais. Porém, a grande maioria dos 330 mil habitantes de Neves trabalha na capital e 
muitos não tiveram liberação de seus empregos para ficar em casa. Ainda que o fluxo de passageiros tenha reduzido consideravelmente, os ônibus continuam sendo ineficientes para que seja possível manter um distanciamento social adequado numa situação de pandemia.

Depois de receber uma foto pelo celular do meu pai, finalmente paramentado com a máscara, é a vez de ligar para minha avó de 79 anos que anda fazendo visitas às amigas da igreja para realizar o culto em casa. No meu bairro, Felixlândia, ainda é muito comum que todos os domingos a gente se encontre com as pessoas na missa ou no culto, pois com uma forte tradição religiosa, as igrejas ainda são os pontos de encontro mais frequentados.

Minha avó até entende que não estejam acontecendo cultos na igreja, mas deixar de rezar em casa já não é coisa de Deus. E nesse momento, em que todos estão com medo de sair de casa, ela acredita que é muito importante pegar firme com o Senhor para que nenhum mal atinja nossos familiares e amigos, e esmorecer na oração está fora de cogitação. Então, em grupos menores e usando máscaras, ela e as amigas da igreja fazem cultos em casa para continuarem intercedendo pelos seus. A minha preocupação como neta é que, apesar de usar máscara, elas continuam dando aqueles abraços calorosos e segurando nas mãos umas das outras na hora de invocar as bençãos.

Então, chega minha vez de ir ao mercado e tenho que enfrentar uma fila de mais de 2 quilômetros na rua apenas para entrar. Para tentar conter a circulação de pessoas dentro dos supermercados, os gestores adotaram uma prática de restringir o acesso a no máximo 10 pessoas por vez. O problema é que enquanto 10 estão lá dentro, aparentemente mantendo o distanciamento social, do lado de fora as pessoas estão aglomeradas por um tempo de espera mínimo de 40 minutos, debaixo do sol quente do meio dia e se aproximando umas das outras para reclamar da falta de logística dos supermercados.

A tarde passa enquanto fazemos todo o processo de lavar as roupas, alimentos e guardar as compras limpas com água sanitária e álcool. Começam também a chegar as primeiras fotos da pista de skate do Santa Fé totalmente reformada e pintada, e os comentários animados dos jovens da Just Crew sobre como a galera ficou animada e realmente "colou no rolé". 


\section{CENA 3- LOTE XV- BELFORD ROXO-RJ}

São 7h da manhã de domingo. É dia de levantar cedo, não para trabalhar, mas sim, dia de curtir o melhor dia da semana: o domingo. Primeiro compromisso é ir à missa na paróquia São Simão, no bairro Lote XV, distrito da cidade de Belford Roxo-RJ. É sempre um prazer ir à Igreja no domingo, pois não é só uma questão de fé, mas também de reencontrar os amigos depois de uma dura semana de trabalho. Nessa região periférica, assim como tantas outras regiões pelo país, os espaços religiosos assumem um papel muito mais de sociabilidade do que religioso, pois muitas vezes é um dos, senão o único, locais de lazer seguros da periferia. (SALES, 2019, p. 16).

A missa começa às 8 horas, minha mãe deixou o café pronto e já saiu na frente, pois ela quer sentar em um bom lugar para ouvir as palavras do padre e ficar perto de suas amigas. Eu já prefiro o "fundão" com os amigos. Após o culto, por voltas das 9 horas, nos reunimos na cantina para falar de futebol, caçoar o time do outro, entre tantos bate-papos.

Domingo no " $\mathrm{XV}$ ", é como chamamos carinhosamente nosso bairro, é dia de muita gente nas ruas, muita gente nos bares, nos mercados e também na feira. Sempre foi assim. Lembro-me que na minha adolescência muitos encontros eram realizados nos campos de várzea, era diversão certa com seus torneios e campeonatos. Contudo, nos dias atuais houve um arrefecimento dessa prática. Os "campos" deram lugar a condomínios de casas populares, ou simplesmente foram invadidos, aos poucos esses espaços de lazer desapareceram. Eram domingos mais felizes, agitados, mas mesmo assim, os domingos no "XV" ainda continuam "badalados". A preferência pela a análise a partir de "domingo", se dá principalmente, por ser o dia com mais moradores de folga. Sábado ainda tem muita gente trabalhando, dessa forma, domingo é o consagrado dia de lazer do "povo do XV".

Após a missa, caminho pela feira, a igreja fica na mesma rua. Passando pela barraca de pastel e caldo-de-cana, revejo alguns amigos que me convidam para saborear um pastel de queijo, eu, para provocar, peço um quibe. Já são 10 e meia da manhã e lembrei que fui incumbido pela família em colaborar com um quilo de carne para o churrasco do almoço. Passei no maior mercado do bairro, pois lá a carne é mais barata. São tantos encontros, tantas pessoas que até aquela despretensiosa compra, torna um espaço de afeto, pois lá também revejo pessoas. Ainda, ao passar pelo caixa, vejo um rosto familiar. A profissional é uma antiga 
vizinha, que me viu crescer, mãe de um antigo amigo que fiz na escola. Ela pergunta sobre minha vida, meu trabalho, enfim, um pequeno bate papo ao passar pelo "caixa".

Saindo do mercado, vejo o relógio, ainda está cedo, dá para voltar à feira e passar no "bar do limão" que serve a melhor caipirinha que já bebi. Naquele momento, ainda não tem nenhum amigo próximo, mas saboreio meu drink, junto com um prato de sardinha frita com limão. O bar fica na principal estrada, e perto do fim da feira, um lugar onde passam os ônibus que circulam pelo bairro, ou seja, quem está no bar, é sempre visto. Nesse momento as lembranças me tomam conta ao ver o "vai e vem" de pessoas. São crianças, idosos, jovens, religiosos, trabalhadores e tantos outros citadinos que passam em frente daquele espaço, que aguçam minha observação em um cotidiano de um domingo numa região de periferia.

Resolvo "dar outra volta" pela feira. Perto das barracas de peixe, tem a barraca do "Seu Severino", que vende carne de porco e tripa frita do mesmo animal. Ele coloca umas cadeiras, uma grande caixa de isopor e vende cervejas. Para quem gosta, tem as bebidas "quentes", como 51 e Caninha-da-roça. A barraca é muito pequena, mas muito cheia, gerando aglomeração. Para "tampar" o sol, ele coloca uma lona azul. Até diminui os raios, mas torna aquele espaço um forno. Contudo, nada tira a empolgação dos frequentadores, que passam a manhã toda "trocando ideias", rindo, muitas vezes sem mesmo se conhecerem. Não é incomum as esposas aparecerem no "Seu Severino" para buscar as compras da feira que os maridos vieram fazer na feira.

Com o passar do tempo chego a casa, os parentes também chegam e "armamos" o tradicional churrasco de domingo em família. Aqui, família não é somente os parentes sanguíneos, mas sim, há uma identificação afetiva. Há muitos compadres sem ser padrinho de ninguém, há muitos irmãos que não tem os mesmos pais, ou seja, simplesmente um tipo de considerção mais carinhosa. São risos, jogos de cartas, dominó, as crianças na piscina, enfim, uma calorosa aglomeração.

Lá perto do fim a tarde, alguém lembra do jogo de futebol na TV às $17 \mathrm{~h}$, jogo de semifinal do campeonato estadual. A maioria da família torce pelo mesmo time, aqueles que são diferentes são caçoados, mas nunca sem perder o respeito. Seria dia de ir ao Maracanã ver o jogo, mas devido ao preço do ingresso, ficamos em casa. Aquele tio mais saudoso lembra que "antigamente" era melhor, pois tinha a "geral" que oferecia ingressos mais baratos. $\mathrm{O}$

\footnotetext{
${ }^{6}$ Antigo espaço no estádio do Maracanã que ficavam as camadas mais populares.
} 
jogo acaba e o nosso time perdeu, mas não há lugar para tristeza, pois , como todo brasileiro, há um debate técnico sobre os erros e acertos do nosso time.

A noite chega, alguns vão embora, há um ar melancólico tão normal de um final de domingo. Contudo, as crianças pedem para ir ao Parque de diversões do bairro. O parque Barilândia existe desde a década de 1970 e resiste firme como um espaço de lazer barato para os moradores do bairro e também de bairros vizinhos, onde as crianças podem brincar em suas atrações.

Nesse espaço de lazer das crianças, há também reencontros dos adultos. Há um grande restaurante, que serve espetinhos e bebidas. Domingo é o dia mais cheio no parque Barilândia. Entre um brinquedo e outro, paramos no bar e os adultos bebem a "saideira". Em uma televisão na parede do bar, as notícias sobre a pandemia parecem não ter fim. Mas, aqui não é lugar pra pensar em coisa ruim não. Aqui é o lugar da resenha, do lazer e de preparar o espírito para mais uma semana, afinal amanhã é segunda-feira, dia de recomeçar a semana e torcer para mais um domingo no " $\mathrm{XV}$ " chegar logo.

Esse codiano de lazer, a princípio, foi profundamente alterado com o avanço da pandemia. Chegavam a informação de amigos contaminados e mortos pela doença. Os meses de março, abril e maio foram dramáticos. A Igreja, a feira e o parque não funcionaram. No entanto, o lazer passou a ser domiciliar. Os encontros de amigos, apesar das recomendações das autoridades, não deixaram de acontecer.

\section{LAZER E PERIFERIA}

É muito comum as pessoas que não conhecem os territórios periféricos associá-los a um local de população miserável, que mora em barracos de madeira (ou de zinco), sem água encanada, esgoto a céu aberto, ausência de energia elétrica, tais como um espaço de universo homogêneo, marcado pela irregularidade na ocupação do solo e pela precariedade em termos de serviços públicos e equipamentos urbanos. Contudo, o contexto periférico é heterogêneo e além dos estigmas sociais, são lugares de memória e cercados de símbolos em que a presença de rituais garante unidade na coletividade. E o que não falta nesses lugares tão densamente povoados, como a Maré, Justinópolis e o Lote XV, são símbolos e rituais. Segundo Manuel Castells (1999, p. 79): 
As pessoas se socializam e interagem em seu ambiente local, seja ele a vila, a cidade, o subúrbio, formando redes sociais entre seus vizinhos. Por outro lado, identidades locais entram em intersecção com outras fontes de significado e reconhecimento social, seguindo um padrão altamente diversificado que dá margem a interpretações alternativas. (...) O provável argumento dos autores comunitaristas, coerente com minha própria observação intercultural, é que as pessoas resistem ao processo de individualização e atomização, tendendo a agrupar-se em organizações comunitárias que, ao longo do tempo, geram um sentimento de pertença e, em última análise, em muitos casos, uma identidade cultural, comunal. (CASTELLS, 1999, p. 79).

Esta percepção equivocada da conformação tipográfica da periferia se estende ao seu morador - o periférico - sendo tratado como se pertencesse a outro grupo social, destoante e distinto do resto da sociedade. As ações que vimos empreendendo estão na contramão desses estigmas que, segundo Erving Goffman (1988, p. 11), são sinais com os quais se procura evidenciar alguma coisa sobre o status moral. Quanto ao sujeito estigmatizado, acrescenta:

Assim, deixamos de considerá-lo criatura comum e total, reduzindo-o a uma pessoa estragada e diminuída. Tal característica é um estigma, especialmente quando o seu efeito de descrédito é muito grande - algumas vezes ele também é considerado um defeito, uma fraqueza, uma desvantagem - e constitui uma discrepância entre a identidade virtual e a identidade social real (GOFFMAN, 1988, p. 12).

A luta na contracorrente exige contra discursos e crítica, em que os espaços são entendidos como de hierarquização. As melhores opções no país, são de lugares reservados para um segmento privilegiado e, portanto, reforçam as supremacias ideológicas com um tipo de reprodução bem teorizada nos estudos de Pierre Bourdieu (2004). E assim como os espaços educacionais, outros setores cumprem as mesmas tarefas de garantir distinção, nos termos que o autor trabalha:

Os agentes sociais estão inseridos na estrutura e em posições que dependem do seu capital e desenvolvem estratégias que dependem, elas próprias, em grande parte, dessas posições, nos limites de suas disposições. Essas estratégias orientam-se seja para conservação da estrutura seja para a sua transformação, e pode-se genericamente verificar que quanto mais as pessoas ocupam uma posição favorecida na estrutura, mais elas tendem a conservar ao mesmo tempo a estrutura e sua posição, nos limites, no entanto, de suas disposições (isto é, de sua trajetória social, de sua origem social) que são mais ou menos apropriadas à sua posição (BOURDIEU, 2004, p. 29).

Ou seja, existem diferentes mecanismos para se ratificar as formas de distinção social. Para muitos, o sujeito favelado é sinônimo de marginal, de violento e de ocioso. Nesse sentido, a população local passa a ser responsável por grande parte dos problemas da 
chamada "cidade legal", como a violência, o desmatamento, a poluição e até mesmo responsável pela fuga de indústrias e empresas das regiões próximas às periferias.

Contudo, olhando para esses espaços para além dos históricos estigmas sociais, observamos nas narrativas acima, nas três periferias pesquisadas, a presença de rituais e espaços de lazer muito marcantes na rotina dos moradores. Talvez essas fortes relações identitárias com esses espaços de lazer explique a grande dificuldade de muitos moradores em abrirem mão deles, inclusive nesse período de pandemia e respectivas restrições sociais.

Na praça de Justinópolis, por exemplo, o grupo Just Crew Skateboard transformou o espaço em território dos skatistas da região. A relação com a praça é muito íntima devido à intervenção do grupo na reforma e limpeza da mesma. Além disso, segundo Goltara Souza (2020, p. 44), o grupo tem uma relação simbólica com a praça, já que muitos deles se conheceram nesse espaço.

\footnotetext{
Alguns solitários jovens nevenses, em momentos distintos, se renderam às ruas em busca de algo que devolvesse o brilho no olhar e a alegria. Acabaram descobrindo, na pracinha de Justinópolis, alguns jovens com seus skates e se aproximaram para observar. Os skatistas mais antigos da praça conheciam muito bem aquele olhar de curiosidade e a solidão por detrás do silêncio observador. E se deixaram conhecer, ao mesmo tempo em que se abriram para conhecer aqueles que passavam pela praça. Mesmo sem saber muito bem o que fazer, os que foram chegando encontraram nesse grupo aquilo que estavam buscando, permitindo que o skate vencesse o silêncio das tardes dando lugar para uma grande crew (palavra em inglês que quer dizer "galera") (GOLTARA SOUZA, 2020, p. 44).
}

Na Maré não é diferente. A relação com os espaços de lazer também é carregada de intensos significados. O Campo da Toca, que existe desde a década de 1980, tem uma rede de ocupação e organização feita pelos próprios moradores. Essa rede organiza os horários, faz a manutenção do campo e organiza as competições, entre ela a principal da região que é a liga da toca.

O campo movimenta uma economia local com a presença de muitos bares a sua volta, já que as resenhas após os jogos são práticas culturais existentes desde a década de 1980 na região. Já no outro lado da Maré, no Morro do Timbau, conhecido por ter um significativo número de moradores idosos, muitas senhoras tem como lazer ir às compras, à igreja e aproveitar esses espaços para encontrar outras vizinhas e colocar o papo em dia. Sobre essa característica, Santos e Vogel (1985) identificaram esse tipo de lazer em estudos realizados no subúrbio do Rio de Janeiro. 
As mulheres encaram como parte do seu lazer o ir "às compras". Nestas ocasiões encontram-se com as amigas e conhecidas. Isto não se dá por sobre o muro do quintal, ou na porta de casa, ou de janela - se dá na rua, o que é indicativo de um inflexão particular da categoria lazer entre os moradores mais tradicionais do bairro (SANTOS; VOGEL, 1985, p. 62).

No Lote XV, a ocupação da rua da feira, principalmente dos seus botequins, é uma marca cultural da região. Com mesas, cadeiras e música ao vivo, os frequentadores do local, que aumenta significativamente aos finais de semana, tecem um ritual etílico nos botequins que são localizados na extensão da feira. É comum ver muitas sacolas dos frequentadores com verduras, frutas, legumes nas mesas e no chão do botequim. Segundo Santos e Vogel, bares em ruas de feiras apresentam rotinas diferentes.

\begin{abstract}
O "estar" marca a relação do bar com os seus frequentadores, é atingindo nos dias de feira por uma mudança que afetam a sociabilidade que lhe é característica. A intensidade de comércio que se desenrola no balcão de bebidas, reduz bastante as relações pessoais que costumam ser mantidas em torno dele. Assuntos e conversas têm de ser adiados, pois, em muitas delas, o próprio barman é um interlocutor indispensável. Além disso, os estranhos passam a ser dominantes, ocupando simultaneamente o bar e o balcão que abriga as panelas fumegantes do angu. Mais numerosos os presentes, são eles que dão o ritmo e o tom das ações no recinto, comendo, bebendo e conversando (SANTOS; VOGEL, 1985, p. 63).
\end{abstract}

Podemos observar que o apego a esses espaços de lazer tem uma construção simbólica e identitária muito forte. Tuan (1983) chama a atenção para o debate sobre espaço e lugar. Segundo o autor, o espaço vira lugar quando uma rede de afetividade é envolvida.

O espaço é símbolo comum de liberdade no mundo ocidental. O espaço permanece aberto; sugere futuro e convida à ação. Do lado negativo, espaço e liberdade são uma ameaça. Ser aberto e livre é estar exposto e vulnerável. O espaço aberto não tem caminho trilhados nem sinalização, Não tem padrões estabelecidos que revele algo, é como uma folha em branco na qual se pode imprimir qualquer significado. (TUAN, 1983, p. 61)

Essa discussão de espaço e lugar reverbera nos estudos do lazer, pois, afinal, estamos falando de espaços ou lugares de lazer? Nascimento (2020) aponta que as periferias urbanas têm como marca a relação íntima dos moradores com o que ele chama de "lugar de lazer". Nesse sentido, a diferença indica que os "lugares de lazer" envolvem uma rede de significações que são ligadas intimamente ao lugar. Ou seja, o "lugar de lazer" é ligado por diversas construções afetivas que fazem aquela prática do lazer só fazer sentido ali, no lugar. Assim, "analisando a construção desses lugares na ótica simbólica e cultural, é possível 
conhecê-los enquanto um espaço que é tecido a partir de um conjunto de práticas sociais importantes para a ressignificação do território" (NASCIMENTO, 2020, p. 111).

Nesse sentido, podemos apontar que os espaços narrados neste trabalho se constituem como "lugares de lazer" devido às relações que os envolvem. Todavia ainda segundo Nascimento (2020), as tessituras sociais que envolvem os lugares de lazer constroem o que ele chama de "lazer topofílico".

\begin{abstract}
Nesse sentido, entendendo o lazer como a cultura - compreendida em seu sentido mais amplo - vivenciada (praticada ou fruída) no tempo disponível pensado como um elemento fundamental na construção dos lugares, podemos refletir sobre as tessituras que envolvem a prática do lazer na relação sujeito/ espaço. Nesse contexto, o lazer topofílico seria o processo de pertencimento e apropriação associado a um Lugar de Lazer que fomenta a formação dos sujeitos enquanto relação social. Assim, o lazer topofílico caracteriza-se pela riqueza de experiências e possibilidades socioculturais constitutivas e constituídas na trama das relações cotidianas que tecem identidades, pertencimentos no processo de ressignificação dos espaços (NASCIMENTO, 2020, p. 114).
\end{abstract}

Entendendo a existência desses lugares de lazer e o lazer topofílico, demasiadamente no contexto periférico, podemos refletir sobre a insistência de alguns moradores da Maré, Justinópolis e Lote XV em infringirem as regras de distanciamento para estarem nesses lugares ricos de significações. Podemos, inclusive, pensar na importância desses lugares no cotidiano das periferias. Lugares que fomentam, segundo Marcellino (2006), o "desenvolvimento pessoal e social, do encontro e da convivencialidade" (MARCELLINO, 2006, p. 70).

Segundo Magnani (1984), é preciso estar atento às realidades que emanam dos territórios periféricos.

Existe toda uma realidade que faz parte do cotidiano dessas populações, mas que normalmente escapa às atenções e foge do interesse político imediato: é o bar da esquina, são os clubes de futebol de várzea, as "casas do norte, os bailes populares (forrós, rodas de samba, funk, soul) e grupos de mutirão. (...) Desconhecer essas formas através das quais se expressa seu universo simbólico ou pensá-las como irrelevantes e até mesmo como empecilhos à ação política imediata pode, entretanto, introduzir um viés na análise dos próprios movimentos reivindicativos, responsável por uma visão distorcida ou superdimensionada de seu alcance político (MAGNANI, 1984, p. 17).

Talvez isso aponte para a importância dos lugares de lazer, mesmo em um contexto de pandemia, na vida desses sujeitos sociais. Assim, podemos trazer para a discussão a importância da dimensão simbólica do espaço em que se desenvolvem as práticas de lazer. 


\section{CONSIDERAÇÕES FINAIS}

As experiências com o espaço acabam por corroborar a construção dos "lugares de lazer" como "lugares memoráveis".

Essa perspectiva apresenta as influências que o lazer tem na relação sujeito/espaço, ampliando assim as dimensões e sentidos do lazer para a sua construção afetiva e memorável com o espaço. Como vimos acima, o espaço, perpassando pela prática de lazer, acaba por transformar-se em algo mais íntimo e pertencente ao indivíduo no qual nomeamos de lugares de lazer.

Becos, vielas, casas pequenas e muito próximas apresentam-se como características de muitas periferias urbanas no país. Essas características acabam transformando a rua e os lugares de lazer como uma extensão da casa na favela. Talvez essas relações afetivas com os lugares explique a dificuldade dos moradores dessas periferias em abrirem mão deles, mesmo em um período pandêmico.

\section{REFERÊNCIAS}

BOURDIEU, Pierre. Os usos sociais da ciência: por uma sociologia clínica do campo científico. São Paulo: editora UNESP, 2004.

CASTELLS, Manuel. O poder da identidade. São Paulo: Paz e Terra, 1999.

CENTRO DE ESTUdOS E AÇÕES SOLIDÁRIAS DA MARÉ. Censo Maré 2000: Quem somos?, [2003?].

CERTEAU, Michel de. A invenção do cotidiano, parte 2. Rio de Janeiro: Vozes, 2013.

FREIRE, Paulo. Pedagogia da esperança: um reencontro com a pedagogia do oprimido. Rio de Janeiro: Paz e Terra, 2014.

GEERTZ, Cliford. A Interpretação das Culturas. Rio de Janeiro: Livros Técnicos e Científicos Editora S.A., 1989.

GOFFMAN, Irving. Estigma: notas sobre a manipulação da identidade deteriorada. 4 ed. Rio de Janeiro: LTC, 1988.

LEITÃO, Leslie; MARTINS, Marco Antônio. Tráfico impõe toque de recolher e uso obrigatório de máscaras em favelas do Rio durante a pandemia. G1, Rio de Janeiro, 8 de maio de 2020. 
Disponível em: https://g1.globo.com/rj/rio-de-janeiro/noticia/2020/05/08/trafico-impoetoque-de-recolher-em-favelas-do-rio-durante-a-pandemia.ghtml. Acesso em: 13 dez. 2020

LIGA DA TOCA PINHEIRO. A bola rola, a partir de hoje às 16:20, com 2 grandes jogos [...]. Rio de Janeiro, 13 de junho de 2020. Página de Facebook. Disponível em: https://www.facebook.com/photo?fbid=151243063131970\&set=a.119576192965324. Acesso em: 15 dez. 2020.

MAGNANI, José Guilherme Cantor. De perto e de dentro: notas para uma etnografia urbana. Revista brasileira de ciências sociais, [S.I.], v. 17, n. 49, p. 11-29, jun. 2002. Disponível em: https://www.scielo.br/scielo.php?pid=S0102-

69092002000200002\&script=sci_abstract\&tlng=pt. Acesso em: 4 jan. 2021.

MAGNANI, José Guilherme Cantor. Festa no pedaço: cultura popular e lazer na cidade. São Paulo: Unesp, 1984.

MARCELLINO, Nelson Carvalho. O lazer e os espaços na cidade. In: ISAYAMA, Hélder, LINHALES, Meily Assbú (org.). Sobre lazer e política: Maneiras de ver, maneiras de fazer. Belo Horizonte: Editora UFMG, 2006. p. 65-92.

MIRANDA, Claudia. Poblaciones afrobrasileñas y COVID-19. Ethos comunitario y otras formas de lucha. In: SEPTIEN, Rosa Campoalegre. La pandemia racializada: debates desde la afroepistemología. Buenos Aires: CLACSO, 2020.

PERES, Ana Cláudia. Favelas contra o vírus: como as periferias vêm lidando com a pandemia de covid-19, em meio aos problemas cotidianos e diante da ausência de ações governamentais. RADIS: Comunicação e Saúde, n. 212, p. 20-25, mai. 2020. Disponível em: https://www.arca.fiocruz.br/handle/icict/41225. Acesso em: 13 dez. 2020.

NASCIMENTO, Diogo Silva do. Maré de lazer: construções, sociabilidades e significados dos lugares de lazer no Morro do Timbau. 2020. Tese (Pós-graduação em Estudos do Lazer da Escola de Educação Física, Fisioterapia e Terapia Ocupacional) - Universidade Federal de Minas Gerais, Belo Horizonte, 2020. Disponível em:

https://repositorio.ufmg.br/handle/1843/34141. Acesso em: 4 jan. 2021.

ORGANIZAÇÃO PAN-AMERICANA DE SAÚDE. Folha informativa COVID-19 - Escritório da OPAS e da OMS no Brasil. Organização Pan-Americana da Saúde, [S.I.], 2020. Disponível em: https://www.paho.org/pt/covid19. Acesso em: 10 nov. 2020.

SALES, Marcelo Ribeiro. Memórias da violência e resistências silenciadas: as ações políticoeducativas da paróquia São Simão, em Belford Roxo (RJ). 2019. Dissertação (Mestrado em Educação, Cultura e Comunicação em Periferias Urbanas) -Universidade Estadual do Rio de Janeiro, Duque de Caxias, 2019.

SÁNCHEZ, F. E. G. Cidade espetáculo: política, planejamento e city marketing, Curitiba, Palavra, 1997. 
SANTOS, Carlos Nelson Ferreira dos; VOGEL, Arno. Quando a rua vira casa. São Paulo: Projeto, 1985.

SOUZA, Rafaela Goltara. Ribeirão das Trevas?: o skate dando um ollie nas narrativas dominantes sobre a cidade de Ribeirão das Neves, MG. 2020. Dissertação (Mestrado em Educação, Cultura e Comunicação em Periferias Urbanas) - Universidade do Estado do Rio de Janeiro, Rio de Janeiro, 2020.

TUAN, Yi-Fu. Espaço e lugar: a perspectiva da experiência. Tradução de Lívia de Oliveira. São Paulo: DIFEL, 1983. p. 76-299.

ZALUAR, Alba; ALVITO, Marcos. Um século de favela. Rio de Janeiro: FGV Editora, 2003. 